\title{
Swyer-James-Macleod Syndrome: The Differential Diagnosis of Unilateral Hyperlucency
}

\author{
Satoshi Hamada and Mitsuhiro Tsukino
}

Key words: Swyer-James-Macleod syndrome, unilateral hyperlucency, differential diagnosis

(Intern Med 57: 2591-2592, 2018)

(DOI: 10.2169/internalmedicine.0725-17)

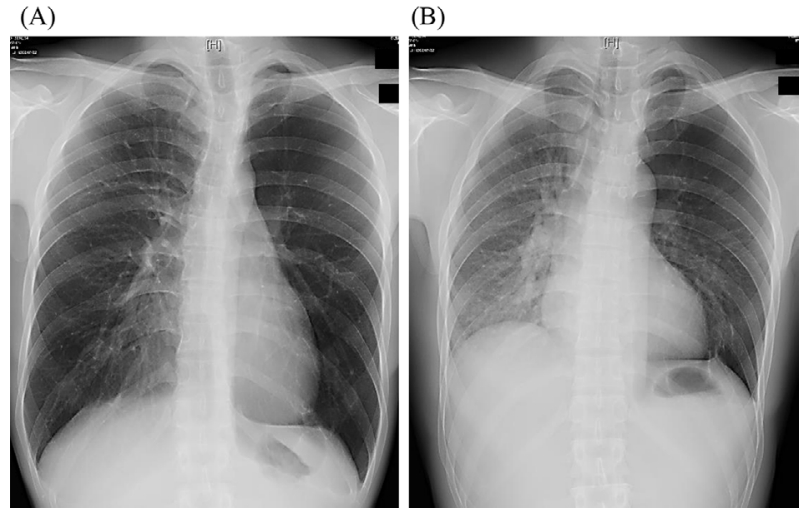

Picture 1.

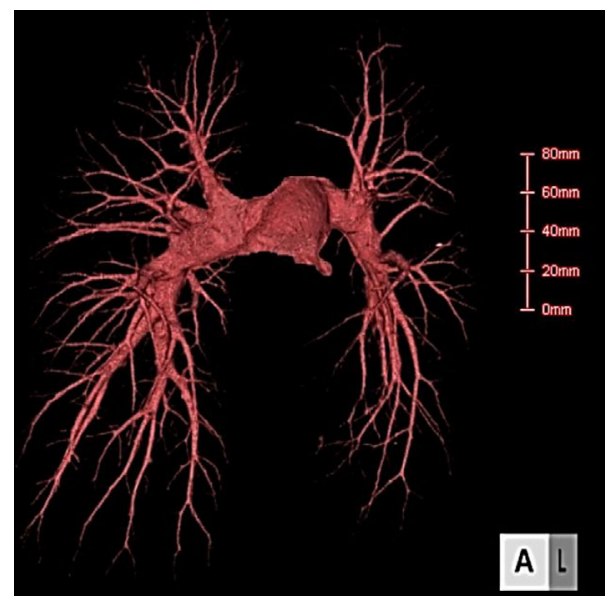

Picture 3.

A 24-year-old male never-smoker who had no remarkable medical history presented to the emergency department with exacerbation of exertional dyspnea. Pulmonary auscultation demonstrated decreased breath sounds in the left lung. Chest $\mathrm{X}$-ray showed hyperlucency in the left lung with air trapping

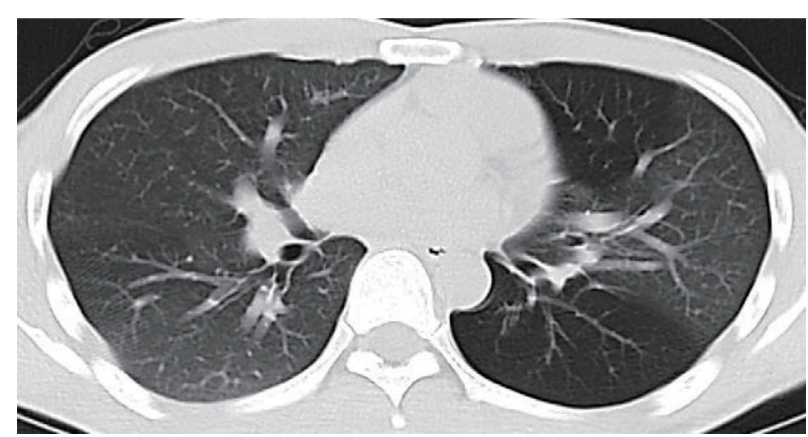

Picture 2.

during expiration (Picture 1A; inspiration, B; expiration). Chest computed tomography revealed a decrease in the density of the left lung, except for in the lingular segment (Picture 2), and hypoplasia of the left main pulmonary artery without any thrombus (Picture 3). A pulmonary function test revealed $4.11 \mathrm{~L}(82.5 \%)$ of forced volume capacity (predicted $\%)$ and $3.00 \mathrm{~L}(67.5 \%)$ of forced expiratory volume in 1 second (predicted\%) without response to bronchodilators. He was diagnosed with Swyer-James-Macleod syndrome (SJMS). SJMS is a disorder characterized by constructive bronchiolitis-induced unilateral hyperlucency (1); however, SJMS can be easily overlooked. Therefore, it is important to consider the possibility of SJMS in order to accurately diagnose and treat patients with unilateral hyperlucency.

The authors state that they have no Conflict of Interest (COI).

\section{Reference}

1. Yekeler E. A rare case of swyer-james macleod syndrome and a new clinical presentation, acquired lobar emphysema. Ann Thorac Surg 93: e123-e125, 2012. 
The Internal Medicine is an Open Access article distributed under the Creative Commons Attribution-NonCommercial-NoDerivatives 4.0 International License. To view the details of this license, please visit (https://creativecommons.org/licenses/ by-nc-nd/4.0/).

(C) 2018 The Japanese Society of Internal Medicine

Intern Med 57: 2591-2592, 2018 